\title{
Cephalobellus lobulata n. sp. (Oxyurida:Thelastomatidae) a Parasite of Neocurtilla claraziana Saussure (Orthoptera: Gryllotalpidae) from Argentina
}

\author{
Nora B Camino ${ }^{+}$, Guillermo R Reboredo
}

Centro de Estudios Parasitológicos y de Vectores, Calle 2, No. 584, 1900 La Plata, Argentina

Cephalobellus lobulata n. sp. (Oxyurida: Thelastomatidae) a parasite of the mole cricket Neocurtilla claraziana Saussure (Orthoptera: Gryllotalpidae) found in Argentina is described and illustrated. It is characterized by a short buccal cavity armed with three teeth, a striated cuticle with the first annule wide with four lobes and the second annule divided in twelve lobes. The male have three pairs of preanal papillae and two pairs of postanal papillae.

Key words: Cephalobellus lobulata n. sp. - Thelastomatidae - Gryllotalpidae - parasite - cricket - taxonomy Argentina

The genus Cephalobellus was proposed by Cobb (1920) who described a nematode from a beetle larva under the name of $C$. papilliger. He described only the male without any diagram of the nematode. Christie (1933) described the genus Scarabanema as a synonym of Cephalobellus (both males were identical), putting $S$. cylindricum as a synonym of $C$. papilliger. Basir (1956) recognized six species from Europe, USA, North India and Brazil. Dale (1964) described another species, $C$. costelytrae, from New Zealand. The genus Cephalobellus contains six species: $C$. papilliger from USA parasited scarabaeid larvae, C. leukarti Christie, 1933 from Germany in scarabaeid larvae, C. brevicaudatum Christie, 1933 from USA in scarabaeid larvae, Blattidae and tipulids, $C$. magalhàesi (Schwenk, 1926) from Brazil in Blattidae, and C. galliardi (Dollfus, 1952) from France in scarabaeid larvae. In this paper we report another species, C. lobulata n. sp. parasitizing nymphs of mole cricket found in Argentina.

\section{MATERIALS AND METHODS}

Third and fourth stages nymphs of Neocurtilla claraziana S. found in Gorina, Buenos Aires Province, Argentina, were collected by hand and then put in individuals vials. In the laboratory, we used the Poinar (1975)'s techniques: first of all we put the insects to sleep at $8^{\circ} \mathrm{C}$ for $10 \mathrm{~min}$, and then we

\footnotetext{
${ }^{+}$Corresponding author. Fax: +54-221-423.2327.

E-mail: cepave@museo.fcnym.unlp.edu.ar

Recieved 13 May 1999

Accepted 27 October 1999
}

dissected them in Petri dishes with distilled water under microscope stereoscope. We found the nematodes (males and females) in the stomodeo intestinal of the insects and then they were killed in distilled water at $60^{\circ} \mathrm{C}$ during $2 \mathrm{~min}$. Posteriorly they were put in a solution of distilled water + TAF $(1: 1)$ during $48 \mathrm{~h}$, finally we finished the fixed in pure TAF.

Living and fixed specimens were employed for drawings and measurements using a camera lucida microscope, and a micrometer in a Zeiss compound microscope. Measurements were for the holotype male and allotype female; for paratypes the range is in parenthesis.

\section{RESULTS \\ Cephalobellus lobulata $\mathrm{n}$. sp. (Figure)}

Description: small nematodes. Body cylindrical. Cuticle conspicuously striated throughout the whole length of the body except the tail. First annule wide with four lobes and the second one divided in twelve lobes. Mouth opening subtriangular, surrounded by eight labiopapillae. Amphids pore-shaped. Buccal cavity short and armed with three teeth. Oesophagus consisting of an anterior cylindrical corpus, an isthmus and a posterior valvular bulb. Excretory pore about one oesophagus width posterior to base of oesophagus. Intestine dilated anteriorly. Vulva protruding and situated in the last posterior third of the body. Ovaries two. Vagina cylindrical and long. Eggs ellipsoidal with smooth shell. Male with a single spicule, without gubernaculum. Anal region protruding. Three pairs of preanal papillae and two pairs of postanal papillae. Tail in both sexes were long, filiform and pointed. 

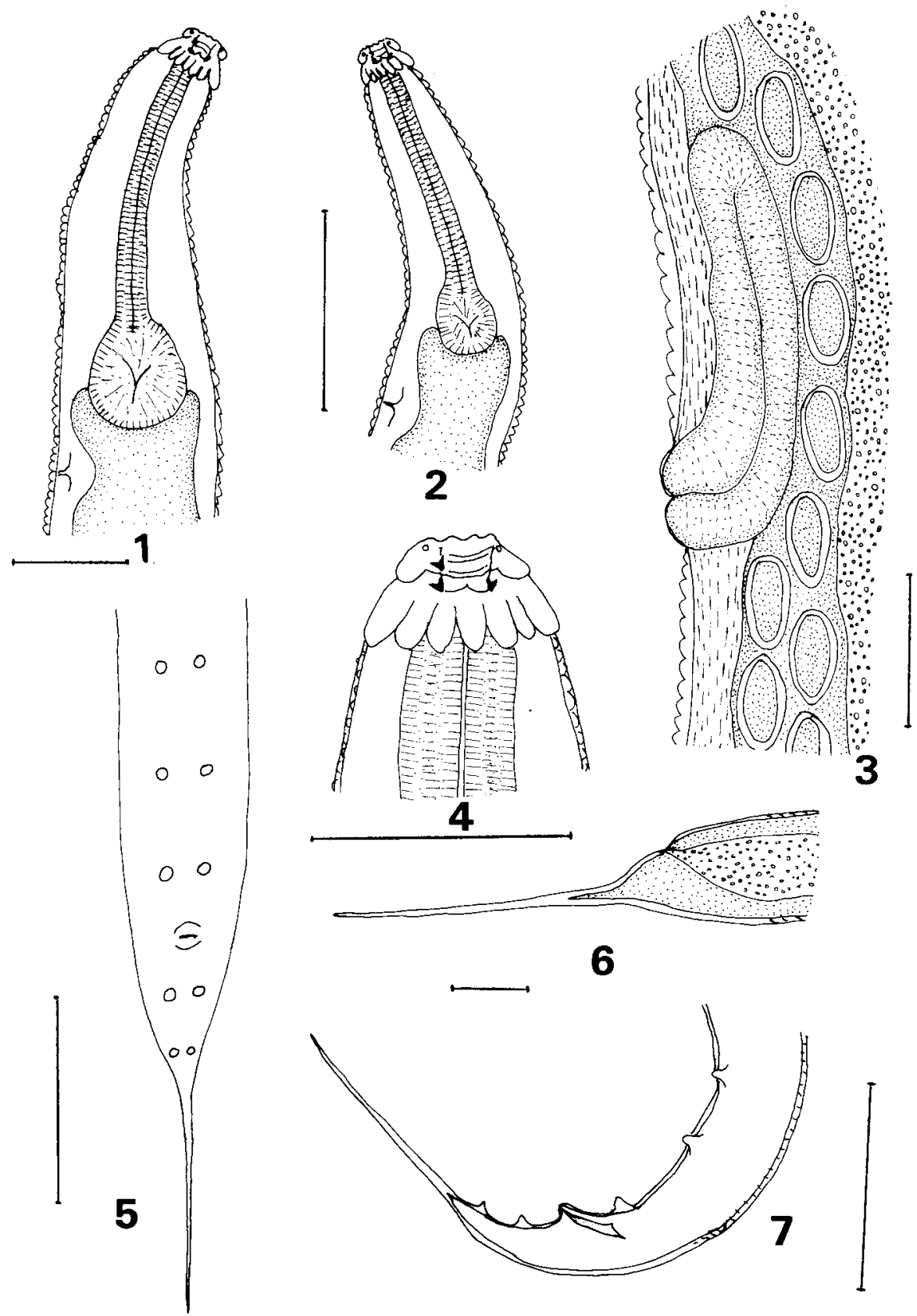

Cephalobellus lobulata n. sp. - 1: anterior end of female; 2: anterior end of male; 3: vagina and eggs; 4: stoma of female; 5: posterior end of male, ventral view; 6: posterior end of female; 7: posterior end of male, lateral view. Bars $=50 \mu \mathrm{m}$.

TABLE

Differences between the closed species

\begin{tabular}{llll}
\hline & Cephalobellus lobulata & \multicolumn{1}{c}{ C. papilliger } & \multicolumn{1}{c}{ C. costelytrae } \\
\hline Buccal cavity & Short and armed & Three pointing triangular & One dorsal and two \\
& with three teeth & cuticular plates & subventral weak tringular teeth \\
Preanal papillae & Three pairs & One pair & One pair \\
Postanal papillae & Two pairs & One pair & Two pairs \\
\hline
\end{tabular}


Male ( $\mathrm{n}=17)$ : body length: $907.1 \mu \mathrm{m}(850-1,105)$; cephalic diameter: $9.4 \mu \mathrm{m}$ (8.6-10.4); oesophagus length: $89.3 \mu \mathrm{m}$ (75.6-95); distance from anterior end to excretory pore: $103.4 \mu \mathrm{m}(95-120.5)$; greatest width: $44.7 \mu \mathrm{m}$ (42-47); spicule length: 18.8 $\mu \mathrm{m}$ (17-19.2); tail length: $61.1 \mu \mathrm{m}$ (59.7-62.5).

Female $(\mathrm{n}=22)$ : body length: $1,610 \mu \mathrm{m}(1,420-$ 1,800); cephalic diameter: $21.2 \mu \mathrm{m}(18.8-23.5)$; oesophagus length: $289.1 \mu \mathrm{m}$ (275-297.8); distance from anterior end to excretory pore: $322 \mu \mathrm{m}$ (305.4332); greatest width: $98.7 \mu \mathrm{m}$ (92-102); diameter of body at level of vulva: $101.05 \mu \mathrm{m}$ (99-105.5); V: 78.3\% (75.4-80.5); vagina length: $124.6 \mu \mathrm{m}$ (116-132); tail length: $199.8 \mu \mathrm{m}$ (196.4-205); length and width of eggs: $25 \mu \mathrm{m}$ (24.2-25.5) x 11.8 $\mu \mathrm{m}$ (11.5-12).

Type host: nymphs of Neocurtilla claraziana Saussure, 1874 (Orthoptera: Gryllotalpidae).

Type locality: Gorina, Buenos Aires Province, Argentina.

Type material: deposited in the Helminthological collection at Cepave, series numbered TC126TC1128.

\section{REMARKS}

C. lobulata n. sp. closely resembles $C$. papilliger Cobb, 1920, and C. costelytrae Dale, 1964 (Table), in the vagina shaped, tail long and filiform in both sexes and the general form of the spicule.

C. papilliger is separated from our new species by having the buccal cavity provided with three inward and forward pointing triangular cu- ticular plates and the male has one pair of preanal papillae in front of anus, one on each side of the anus, one median postanal double papilla slightly posterior to the anus and a pair of postanal papillae behind the anus.

C. costelytrae differs from C. lobulata $\mathrm{n}$. sp. in having the buccal cavity with one dorsal and two subventral weak triangular teeth at base and the male has a pair of prominent preanal papillae, a pair of adanal papillae, ventro-laterally placed, a double ventral papilla inmediately posterior to the anus, and a pair of caudal papillae about one-third of the length of the tail posterior to the anus.

C. lobulata $\mathrm{n}$. sp. can be distinguished meanly by having the buccal cavity short and armed with three teeth, cuticle striated with the first annule wide with four lobes and the second annule divided in twelve lobes and the male has three pairs of preanal papillae and two pairs of postanal papillae.

\section{REFERENCES}

Basir MA 1956. Oxyuroid parasites of arthropoda. A monographic study. Zool Sttutgart 38: 1-79.

Christie JR 1933. The generic names Cephalobellus Cobb, 1920 and Scarabanema Christie, 1931 (Nematoda). J Wash Acad Sci 23: 358.

Cobb NA 1920. One hundred new nemas. Contrib Sci Nematol 9: 245.

Dale PS 1964. A new species of Cephalobellus (Nematoda:Thelastomatidae) from the larva of Costelytra zelandica (Coleoptera:Melolonthinae). NZ J Sci 7: 596-601

Poinar Jr GO 1975. Entomogenous Nematodes. A Manual and Host List of Insect-Nematode Associations, Brill ed., Leiden, 317 pp. 